\title{
2555. Shaking table testing and numerical modeling of continuous welded ballast track on bridges under longitudinal seismic loading
}

\author{
Ping Wang ${ }^{1}$, Hao Liu ${ }^{2}$, Xiankui Wei ${ }^{3}$, Rong Chen ${ }^{4}$, Jieling Xiao ${ }^{5}$, Jingmang Xu ${ }^{6}$ \\ MOE Key Laboratory of High-Speed Railway Engineering, Southwest Jiaotong University, \\ Chengdu, 610031, China \\ School of Civil Engineering, Southwest Jiaotong University, Chengdu, 610031, China \\ ${ }^{3,4}$ Corresponding author \\ E-mail: ${ }^{1}$ wping@home.swjtu.edu.cn, ${ }^{2} 864845592 @ q q . c o m,{ }^{3}$ wei_xiankui@my.swjtu.edu.cn, \\ 4swjtucr@hotmail.com, ${ }^{5} x j l i n g @ h o m e . s w j t u . e d u . c n,{ }^{6}$ mang080887@163.com
}

Received 15 September 2016; received in revised form 18 June 2017; accepted 4 July 2017

DOI https://doi.org/10.21595/jve.2017.17735

Check for updates

Abstract. In order to confirm the validity of the ideal elasto-plastic resistance model applied to the ballast track under seismic loading, this paper studies the seismic response of continuous welded ballast track on bridges through the shaking table test and presents a process of updating the model based on the test results. The results indicate that the track constraint can improve the low order natural frequency of bridges significantly, and reduce the displacement response of the bridge. When ballast beds are effectively in a dynamic reciprocating state while under seismic loading, a structural change between the granules will occur, wherein some will flow and redistribute. The dynamic hysteretic change of the ballast longitudinal resistance is complex and quite different from that of the ideal elasto-plastic hysteretic route, and the ballast longitudinal resistance performance degenerates. If ballast longitudinal resistance is assumed to be ideal elastic-plastic resistance, the actual beam displacement response will be underestimated and the calculated rail seismic force will be greater than the test result. Moreover, the equivalent stiffness coefficient $K_{e}$ and damping coefficient $C_{e}$ of the ballast dynamic resistance characteristics could be obtained by model updating, and the simulation results coincide well with the test results.

Keywords: CWR on bridges, ballast track, seismic response, shaking table test.

\section{Introduction}

Technology of continuous welded rail (CWR) on bridges is one of the core technologies in modern railway tracks, and provides a strong technical support for high-speed and heavy load railway transportation etc. [1]. Ballast beds on bridges have been accepted by most of the countries in the world due to their characteristics of good structural elasticity, excellent damping performance and easy maintenance $[2,3]$. However complicated operation environments and potential natural hazards are great challenges to railway safety and long-term reliable operation. Frequent natural hazards are a severe persistent threat to railway safety $[4,5]$.

Since track and bridge structures have considerable interaction, and rails have unevenly distributed additional forces such as contractility, bending and braking forces. Rail strength, stability and breakage all have a close relationship with the distribution of longitudinal forces in the rails $[6,7]$. Ballast longitudinal resistances, as key design parameters for track structures, are very important for improving the uniformity of rail longitudinal forces, and ensure line stability and train operation safety. The reasonable magnitude and distribution of ballast longitudinal resistance has a direct impact on the longitudinal stability of track structures, the track creepage and the design of CWR on bridges [8, 9]. However, when a bridge structure gives a dynamic response under seismic loading, the load will be transmitted to the ballast bed, and the granular ballast bed structure and ballast resistance will change under seismic loading [10], which will then react upwardly on the track structure, changing the strained state of the track and therefore the longitudinal track-bridge interaction will become very complicated under seismic loading. Among existing research into the seismic response of CWR on bridges, the ideal elastic-plastic resistance 
has been used in both ballast and ballastless track. Toyooka et al. modeled the behavior of the ballastless track structure under seismic loading, and the results proved that the characteristics of the fastener resistance exhibited approximately ideal elastic-plastic properties [11]. Fitzwilliam used an ideal elastic-plastic material to simulate the rail-structure interaction of a ballast track when subjected to a train braking load and a seismic load [12]. Petrangeli analyzed the displacement time-history response of a continuous welded ballast track on a bridge based on the assumption of elastic-plastic resistance [13]. Iemura et al. tested the influence of ballast track constraints on the seismic response of isolated bridges, the results showed that the ballast resistance could be modeled by a bi-linear friction model [14]. Esmaeili developed an FE model for a seismic analysis of ballast railway track, and the ballast layers were modeled using a series of lumped masses connected by springs and dashpots to simulate the ballast longitudinal resistances [15].

Ballast beds are packed granular structures, which are subject to structural change under seismic loading due to interaction between the granules, and part of the granules will flow and redistribute [16], causing a strong nonlinearity and uncertainty of longitudinal resistance and influences the rail stability and strained state etc. Existing research findings on longitudinal track-bridge interaction models used under uniform seismic excitation, have failed to fully account for the damage and repacking of granular ballast beds which occur, and its influence on key parameters. Those function-based constant resistance models, variable resistance models or ideal cyclic-hysteretic models etc. are yet to be proved.

Hence, in this paper, a test model for continuous welded ballast track on bridges is established, primarily to analyze the straining, deformation and ballast bed degradation of CWR on bridges under seismic loading, observe granular ballast motion, track-bridge displacement, rail longitudinal stress transmission etc., and make a comparison with those numerical simulation results and discuss the assumed ideal cyclic-hysteretic model of ballast longitudinal resistance.

\section{Test of dynamic interaction of the track-structure system}

\subsection{Test purpose}

According to existing research (based on the longitudinal track-bridge interaction), the rail longitudinal force under seismic loading is several times larger than that of the temperature condition $[13,15]$. Therefore, the seismic effect on rail longitudinal forces should be considered when designing CWR on bridges across the seismic zone. Compared with vertical and transverse seismic vibrations, the longitudinal seismic vibrations have the most direct and important effect on rail longitudinal force. In addition, the track longitudinal resistance is also an important parameter in the structural design of CWR on the bridge. For ballast track, the nonlinearity of track longitudinal resistance under seismic loading is significant, especially under longitudinal seismic loading. Therefore, this paper focuses on longitudinal seismic vibrations, and a test model of continuous welded ballast track on bridges was designed and established, and the following three aspects were investigated.

1) An analysis of the influence of bridge motion caused by earthquakes on the performance of granular ballast beds and its resistance;

2) A study of the changing longitudinal rail forces under seismic loading;

3) A verification of the rationality of the ideal elasto-plastic resistance model applied to the ballast track under seismic loading, which can be used as a reference for modifying the theoretical model.

\subsection{Seismic response simulator}

A test was carried out with a strong earthquake response simulator machine. The specifications of which are as follows: 
Table size: $7.0 \mathrm{~m} \times 2.0 \mathrm{~m}$ (a design especially extended for this test); shaking direction: horizontal single direction; Max. Stroke: \pm 100 mm; Max. Acc: $1.2 \mathrm{~g}$; Weight limit: 25 ton.

The experimental earthquake response simulating test consists of servo control system, shaking table, support system, vibration exciter system, and hydraulic system. In this paper, the experimental test used the acceleration as control signals to control the shaking table. The seismic acceleration waves were input as excitation by the servo control system, and the parametric generator converted the seismic waves into the acceleration parameter signals and control the movement of the shaking table through the servo controller, as shown in Fig. 1.
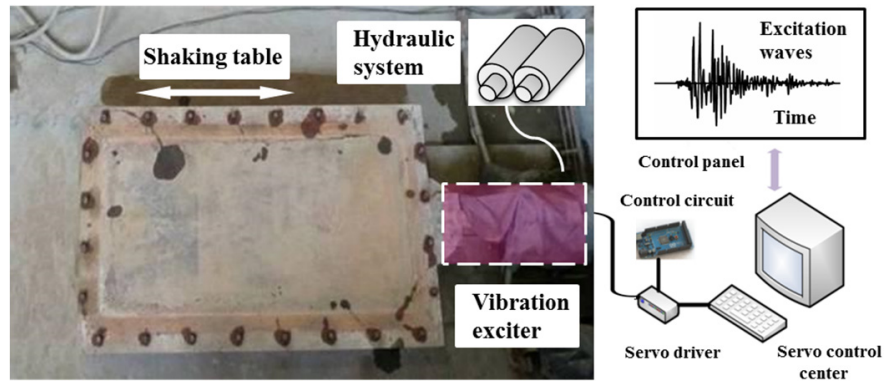

Fig. 1. Strong earthquake response simulator

\subsection{Test model}

As shown in Fig. 2, the test model consists of the ballast track, two beams of different lengths, and the adjacent abutment part. The bridge beams were RC slab boards of $2.0 \mathrm{~m}$ in length $\times 2.0 \mathrm{~m}$ in width $\times 0.20 \mathrm{~m}$ in height and $3.9 \mathrm{~m}$ in length $\times 2.0 \mathrm{~m}$ in width $\times 0.20 \mathrm{~m}$ in height, which were supported by rubber bearings fixed on the shaking table. The abutment was a rigid steel frame, tightly fastened to the table, and the total weight of the model was about 13 tons.

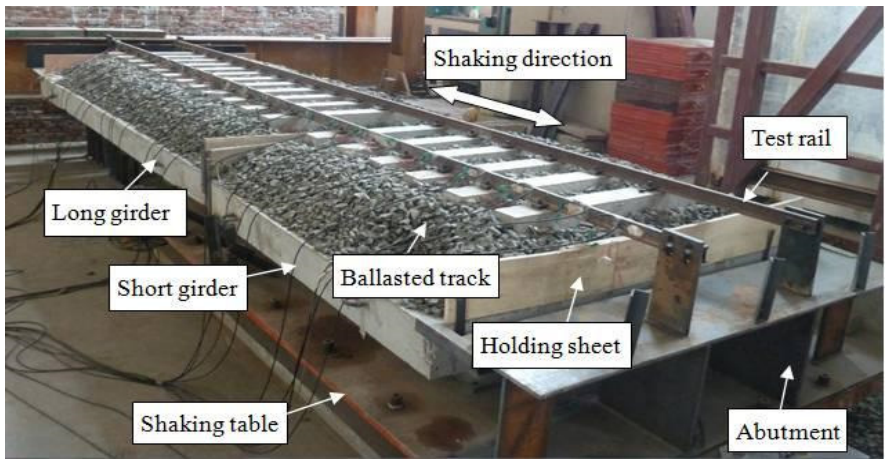

Fig. 2. Test model

The detailed design of the model is shown in Fig. 3. The scaled rail ( $4 \mathrm{~kg}$ rail track), with the sectional area of $5.1 \mathrm{~cm}^{2}$ and length of $7 \mathrm{~m}$, was fixed to the abutment at one end and free at the other end. Microcellular rubber pads were placed between the rail and sleeper and strongly held by special fasteners so as to ensure there was no relative displacement between the rail and sleeper. The ballast bed was $1.4 \mathrm{~m}$ in top width, $2.0 \mathrm{~m}$ in bottom width, and $0.15 \mathrm{~m}$ in height, with a size distribution of 10.5-31.5 mm. Furthermore, the ballast bed weighed $655 \mathrm{~kg}$ per meter including rail and sleeper, and the bridge beams weighed $4134 \mathrm{~kg}$ and $2120 \mathrm{~kg}$ respectively. In order to simulate the actual structure of the bridge, the beam was supported by four rubber bearings; the design parameters of the bearing are shown in Table 1. Among them, the long beam was supported by RB A, and the short beam was supported by RB B. In the test model, the ballast resistance at the beam gap was ignored, and a holding sheet was set to prevent the scatter of ballast. 


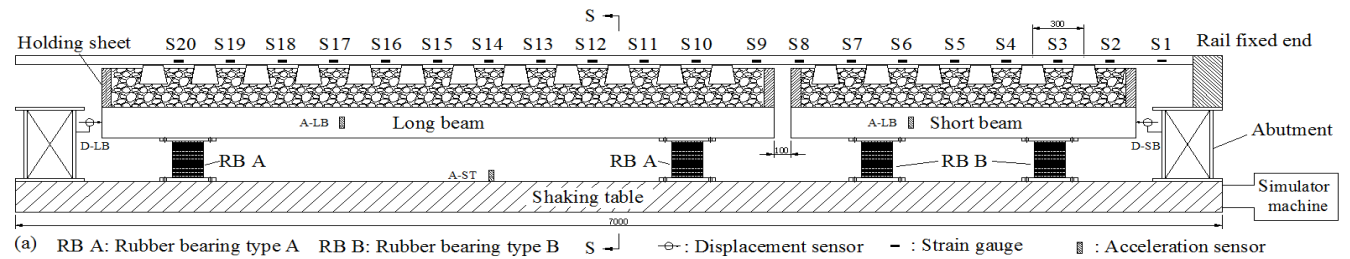

a) Model front view

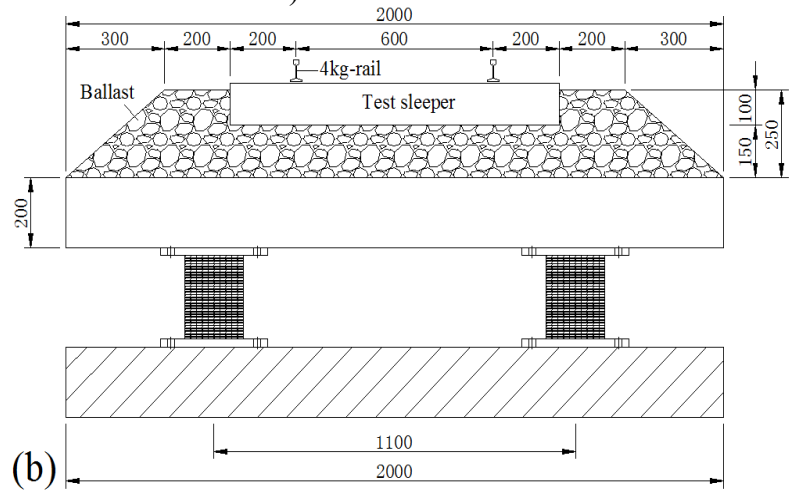

b) Model cross section S-S

Fig. 3. Schematic view of test setup

Table 1. Design parameters of rubber bearings

\begin{tabular}{|c|c|c|}
\hline Parameter Type & Type A & Type B \\
\hline Baseplate & $22 \mathrm{~mm} \times 325 \mathrm{~mm} \times 325 \mathrm{~mm}$ \\
\hline Bearing section dimension & $180 \mathrm{~mm} \times 180 \mathrm{~mm}$ & $200 \mathrm{~mm} \times 200 \mathrm{~mm}$ \\
\hline Rubber layer arrangement & $6 \mathrm{~mm} \times 30$ & $5 \mathrm{~mm} \times 30$ \\
\hline Lined plate layout & $2 \mathrm{~mm} \times 29$ & $3 \mathrm{~mm} \times 29$ \\
\hline Shore A hardness of rubber & 50 & 65 \\
\hline Shear modulus & $0.64 \mathrm{MPa}$ & $1.0 \mathrm{MPa}$ \\
\hline
\end{tabular}

\subsection{Sensor layout}

For the shaking table model test, three acceleration sensors, two displacement sensors and twenty rail strain gauges were arranged, the sensor layout illustration is shown in Table 2 . The model loading control and data collection system features actuator, sensor, and data collection units $[11,14]$. The actuator units are controlled with an electrohydraulic servo driven HS-25t seismic simulation platform, and the sensor units are comprised of a force and displacement sensors. In addition, rail stress is measured with a resistance strain gauge, and a CW-YB-2 displacement sensor (range: $\pm 50 \mathrm{~mm}$, accuracy: $0.01 \mathrm{~mm}$ ). For the data collection unit, the DHDAS dynamic signal analyzer is used for real-time data collection and recording. The seismic wave input by the actuator of the seismic simulation vibration platform is recorded accurately with a high-precision acceleration probe.

Table 2. Sensor layout

\begin{tabular}{|c|c|c|c|}
\hline Sensor type & Identifier & Location & Test content \\
\hline \multirow{3}{*}{ Acceleration } & A-ST & Shaking table & \multirow{3}{*}{ Absolute acceleration } \\
\cline { 2 - 3 } & A-LB & Long girder surface & \\
\cline { 2 - 3 } & A-SB & Short girder surface & \\
\hline \multirow{2}{*}{ Displacement } & D-LB & Long beam end & \multirow{2}{*}{ Relative displacement } \\
\cline { 2 - 3 } & D-SB & Short beam end & \\
\hline Strain & S1-S20 & Rail web & Rail axial stress \\
\hline
\end{tabular}




\subsection{Loading method}

When discussing the seismic response of CWR on bridges, one of the important tasks is the reasonable selection of seismic waves and three methods are widely adopted as follows [16, 19]:

1) The actual recorded seismic wave at the location of bridge. This method is an ideal situation. In general, it is unrealistic to obtain the actual seismic wave record at the location of bridge.

2) The existing recorded seismic waves in the past inland earthquakes. According to the existing research achievements, the typical El-Centro wave, Kobe wave, WenChuan wave, Taft wave and Tianjin wave etc. are selected as inputs of the ground motions for the study of seismic behavior of bridge structures.

3) Synthetic seismic waves. The seismic waves are synthesized based on the statistical characteristic values of seismic wave spectrum, acceleration peak, and duration time etc.

This paper mainly aims to explore the seismic response characteristics of continuous welded ballast track on bridges under earthquakes. Therefore, among the existing recorded seismic waves, the typical El-Centro seismic wave (America, 1940, NS), Kobe (Japan, 1995, NS) seismic wave and WenChuan (China, 2008, EW) seismic wave were selected as inputs of the ground motions for the model. The ground motion acceleration waves are shown in Fig. 4, with primary frequencies of $1.46 \mathrm{~Hz}, 1.45 \mathrm{~Hz}$ and $2.34 \mathrm{~Hz}$, respectively. When discussing the dynamic response of continuous welded ballast track on bridges under seismic loading, the acceleration peak values were set to $0.1 \mathrm{~g}, 0.2 \mathrm{~g}$ and $0.4 \mathrm{~g}$. The test conditions are shown in Table 3.

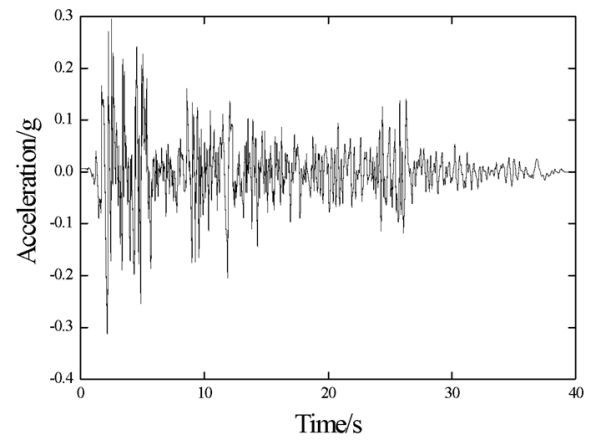

a) El-Centro record

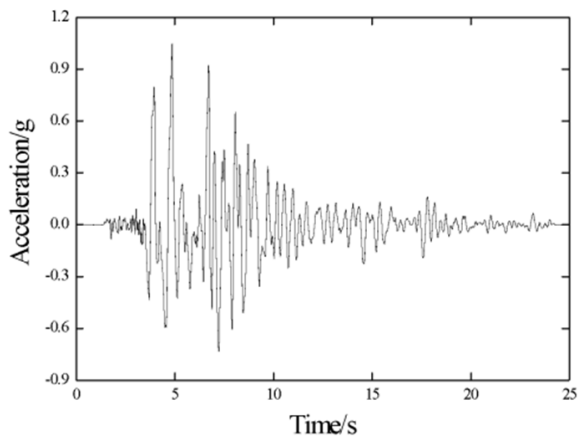

b) Kobe record

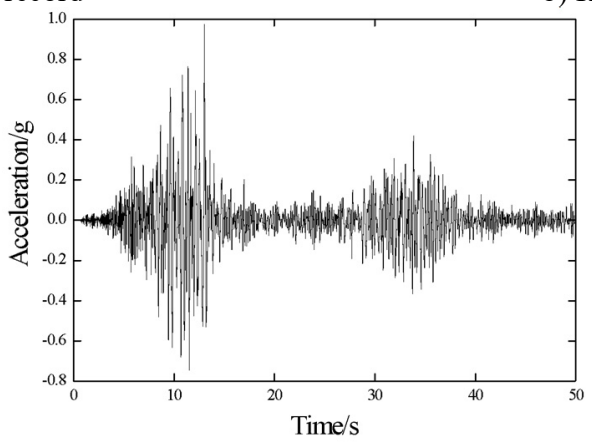

c) Wenchuan record

Fig. 4. Ground motion acceleration waves

\section{Model structure parameter testing}

\subsection{Beam longitudinal stiffness}

The longitudinal stiffness of the bridge beams was tested after the laying of ballast bed, and the stiffness values were $1.00 \mathrm{kN} / \mathrm{mm}$ and $3.85 \mathrm{kN} / \mathrm{mm}$ respectively. 
Table 3. Test conditions

\begin{tabular}{|c|c|c|c|}
\hline Case & Ground motion & Peak acceleration & Notes \\
\hline EL-0.1 g & \multirow{3}{*}{$\begin{array}{l}\text { El-Centro } \\
\text { record }\end{array}$} & $0.1 \mathrm{~g}$ & \multirow{9}{*}{$\begin{array}{l}\text { Ballast bed needed to be tamped again before } \\
\text { each test }\end{array}$} \\
\hline EL-0.2 g & & $0.2 \mathrm{~g}$ & \\
\hline EL-0.4 g & & $0.4 \mathrm{~g}$ & \\
\hline KB-0.1 g & \multirow{3}{*}{ Kobe record } & $0.1 \mathrm{~g}$ & \\
\hline KB-0.2 g & & $0.2 \mathrm{~g}$ & \\
\hline KB-0.4 g & & $0.4 \mathrm{~g}$ & \\
\hline WC-0.1 g & \multirow{3}{*}{$\begin{array}{l}\text { Wenchuan } \\
\text { record }\end{array}$} & $0.1 \mathrm{~g}$ & \\
\hline WC-0.2 g & & $0.2 \mathrm{~g}$ & \\
\hline WC- $0.4 \mathrm{~g}$ & & $0.4 \mathrm{~g}$ & \\
\hline
\end{tabular}

\subsection{Ballast and fastener longitudinal resistance}

The ballast longitudinal resistance and fastener longitudinal resistance tests are shown in Fig. 5(a) and Fig. 5(b). The ballast average longitudinal resistance was $1186 \mathrm{~N}$ with a sliding displacement of $2 \mathrm{~mm}$, as shown in Fig. 6(a). According to assumptions in the existing theory, the ideal elastic-plastic resistance curve is shown in Fig. 6(b). Furthermore, the fastener longitudinal resistance is far greater than the ballast longitudinal resistance, which can be considered as a linear variation, with a linear stiffness of $31 \mathrm{kN} / \mathrm{mm}$.

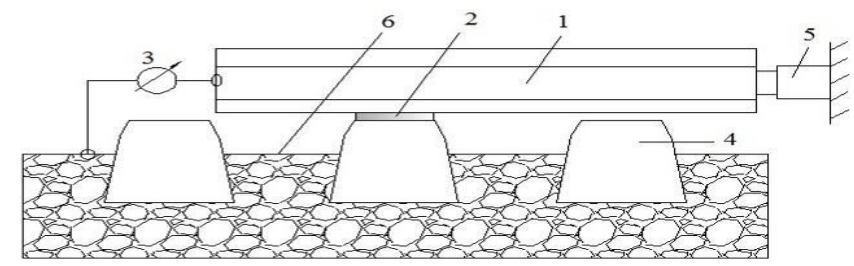

a) Ballast longitudinal resistance test: 1 - test rail; 2 - consolidation component; 3 - displacement meter; 4 - test sleeper; 5 - hydraulic jack; 6 - ballast bed

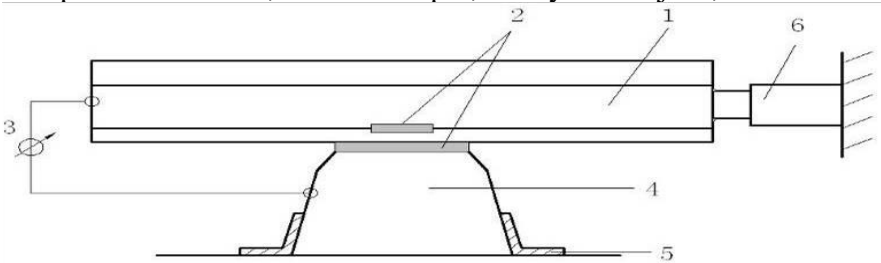

b) Fastener longitudinal resistance test: 1 - test rail; 2 - special fastener;

3 - displacement meter; 4 - test sleeper; 5 - rigid support; 6 - hydraulic jack

Fig. 5. Test method for ballast and fastener longitudinal resistance

\subsection{Beam's natural frequency and damping ratio}

During the shaking table test, one of the most important tasks is to identify the dynamic parameters of the structure, and the sweeping frequency of white noise excitation is the most commonly used method [17]. Before the installation of the test rail, the stationary gauss white noise excitation was input. The bridge beam's natural vibration frequency was identified by calculating the frequency response function through the measured acceleration record. Additionally, the damping ratio of the first order frequency was calculated by the half-power bandwidth method. The results are shown in Table 4 .

The bridge beam natural vibration frequency coincides well with the theoretical results, thereby proving the accuracy of the beam longitudinal stiffness test results. Furthermore, the bridge beam damping ratio coincides well with the natural rubber equivalent damping ratio [18]. In this paper, the damping ratio is taken as 0.03 for calculations. 


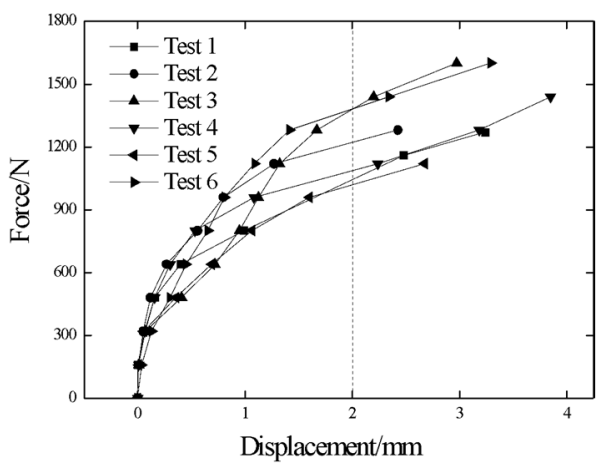

a) Ballast longitudinal resistance

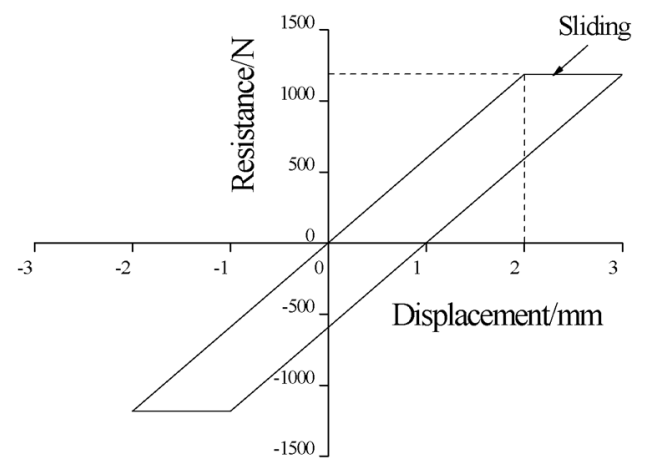

b) Ideal elastic-plastic resistance

Fig. 6. Ballast longitudinal resistance test results

Table 4. Natural frequency and damping ratio

\begin{tabular}{|c|c|c|c|c|}
\hline \multirow{2}{*}{ Beam } & \multicolumn{3}{|c|}{ Natural frequency } & \multirow{2}{*}{ Damping ratio } \\
\cline { 2 - 4 } & Test & Theory & Deviation & \\
\hline Long beam & 1.88 & 1.94 & $3.2 \%$ & 0.032 \\
\hline Short beam & 6.07 & 5.45 & $10.2 \%$ & 0.026 \\
\hline
\end{tabular}

\section{Numerical analysis method}

The finite element simulation technique is a relatively mature and widely adopted method for discussing the seismic response of CWR on bridges $[13,15]$. In comparing the test results with the theoretical results, the plane finite element model for seismic response analysis of CWR on bridges was established, which was suitably simplified.

\subsection{Numerical model}

In regards to the continuous welded ballast track on bridges, during testing the ballast bed is subject to a dynamic reciprocating state under seismic loading, a change in the structure between granules will occur, wherein some will flow and redistribute. The dynamic hysteretic change of the ballast longitudinal resistance is complex and quite different from that of the ideal elasto-plastic hysteretic route. Therefore, in order to analyze the influence of nonlinear cyclic hysteretic characteristics of granular ballast beds on the strained state of rail under seismic loading, a CWR on bridge calculation model under seismic excitation is established based on the structural parameters of the test model (see Fig. 7), which can primarily be used to analyze the track-bridge displacement and rail longitudinal stress transmission etc. and perform a contrast analysis with those measured under an ideal elasto-plastic resistance. The longitudinal stiffness and damping ratios of beam supports were measured according to the characteristics of the structural parameters characteristics. In addition, the beam was coupled with the mass of the body itself and the ballast bed (including the ballast, sleeper, and rail), and the total mass of which is a known value. The seismic wave input by the seismic simulation vibration platform was also recorded accurately with a high-precision acceleration probe.

\subsection{Vibration equation}

When discussing the seismic response of CWR on bridges, due to the strong nonlinearity of structural dynamic responses, the nonlinear time-history step-by-step integration method is adopted $[14,19]$. In addition, structural damping is an important dynamic parameter that causes energy dissipation during vibration, thus, the structure's damping information must be introduced through a reasonable and reliable dynamic finite element analysis model. From a practical point of view, the Orthogonal damping model-Rayleigh method was adopted. The structural vibration 
equation under seismic loading can be expressed as follows:

$[M]\{\ddot{x}(t)\}+[C]\{\dot{x}(t)\}+[K]\{x(t)\}=-[M][I]\left\{\ddot{x}_{g}(t)\right\}$.

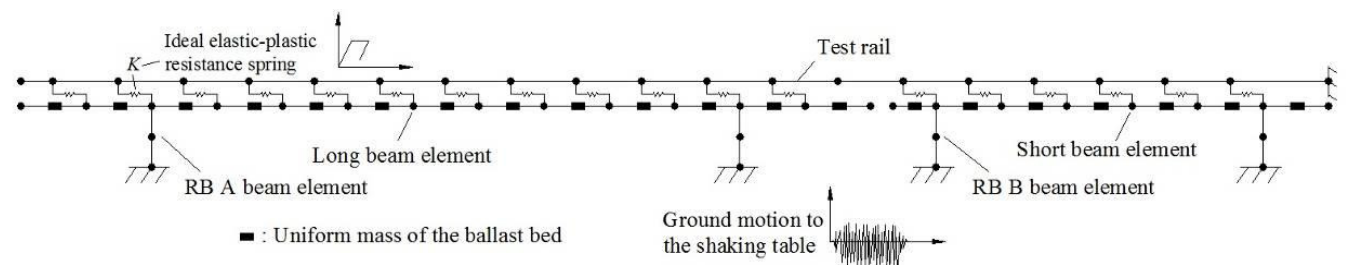

Fig. 7. Numerical calculation model of test structure

The above equilibrium equation for a nonlinear time interval analysis can be expressed by the following increment within a minor time interval $\Delta t$ :

$[M]\{\Delta \ddot{x}(t)\}+[C]\{\Delta \dot{x}(t)\}+[K]\{\Delta x(t)\}=-[M][I]\left\{\Delta \ddot{x}_{\mathrm{g}}(t)\right\}$,

where $[M],[C]$, and $[K]$ refer to the mass matrix, damping matrix, and stiffness matrix of the system respectively; $\{\ddot{x}(t)\},\{\dot{x}(t)\}$, and $\{x(t)\}$ refer to the acceleration, speed, and displacement time interval in relation to the subgrade ground, respectively; $[I]$ refers to the influence matrix; and $\left\{\ddot{x}_{g}(t)\right\}$ refers to the seismic wave acceleration time interval within the subgrade ground. The damping matrix can be expressed based on the Rayleigh method [20] as follows:

$[C]=\alpha[M]+\beta[K]$

where $\alpha$ and $\beta$ refer to the mass damping coefficient and stiffness damping coefficient respectively, which can be calculated based on the damping ratios as follows:

$\alpha=\frac{2 \omega_{i} \omega_{j}\left(\xi_{i} \omega_{j}-\xi_{j} \omega_{i}\right)}{\omega_{j}^{2}-\omega_{i}^{2}}$,

$\beta=\frac{2\left(\xi_{j} \omega_{j}-\xi_{i} \omega_{i}\right)}{\omega_{j}^{2}-\omega_{i}^{2}}$,

where $\omega_{i}$ and $\omega_{j}$ refer to the natural frequencies of the $i$ th and $j$ th order of the structure, respectively; and $\xi_{i}$ and $\xi_{j}$ refer to the damping ratios in relation to the $i$ th and $j$ th order. In regards to the test detailed in this paper, the longitudinal first-order natural frequencies of the long and short beams were calculated. The vibration mode damping ratio was set at 0.03 .

\subsection{Equation solution}

In general, the structural vibration Eq. (1) is difficult to calculate based on analytical methods. Common methods, such as central difference, linear acceleration, Newmark- $\beta$, Wilson- $\theta$, and Houbolt, are subject to step-by-step integration. Calculations in this paper have adopted the Newmark- $\beta$ method. As early as 1959 , Newmark presented the Newmark- $\beta$ numerical analysis method for calculating the differential equation of structural dynamic equilibrium [21, 22], according to which, the hypothetical changing speed and displacement increment during the integrating process is shown below:

$$
\left\{\begin{array}{l}
\{\dot{x}(t+\Delta t)\}=\{\dot{x}(t)\}+(1-\gamma)\{\ddot{x}(t)\} \Delta t+\gamma\{\ddot{x}(t+\Delta t)\} \Delta t, \\
\{\ddot{x}(t+\Delta t)\}=(\{x(t+\Delta t)\}-\{x(t)\}) \frac{1}{\beta \Delta t^{2}}-\{\dot{x}(t)\} \frac{1}{\beta \Delta t}-\left(\frac{1}{2 \beta}-1\right)\{\ddot{x}(t)\},
\end{array}\right.
$$


where $\{\ddot{x}(t+\Delta t)\},\{\dot{x}(t+\Delta t)\}$, and $\{x(t+\Delta t)\}$ refer to the acceleration, speed, and displacement array of the entire system respectively at $t+\Delta t$; and $\{\ddot{x}(t)\},\{\dot{x}(t)\}$, and $\{x(t)\}$ refer to the acceleration, speed, and displacement array of the entire system respectively at $t$.

In addition, $\Delta t$ refers to the integrating time step; and $\gamma$ and $\beta$ refer to constants depending on integrating accuracy and stability.

In this paper, the analysis is based on the Newmark- $\beta$ method. The integral parameters used for the calculation are $\gamma=0.5$ and $\beta=0.25$ respectively.

\section{Test and numerical results}

\subsection{Seismic response without track constraint}

Without track constraint (irrespective of ballast longitudinal resistance), the structural dynamic response has the typical properties of an SDOF system. The seismic response of the beam could be obtained (acceleration and displacement) by inputting seismic waves through the shaking table. The test and theoretical results of the maximum acceleration and displacement of the beam are shown in Table 5. Furthermore, taking WC- $0.1 \mathrm{~g}$ as an example, the comparison of long beam seismic response is shown in Fig. 8.

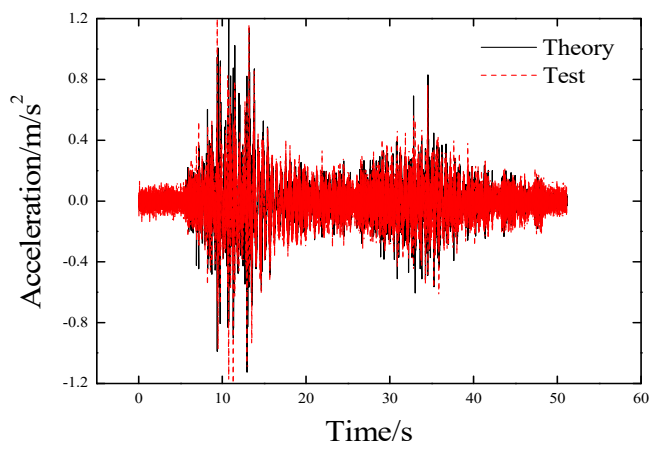

a) Long beam

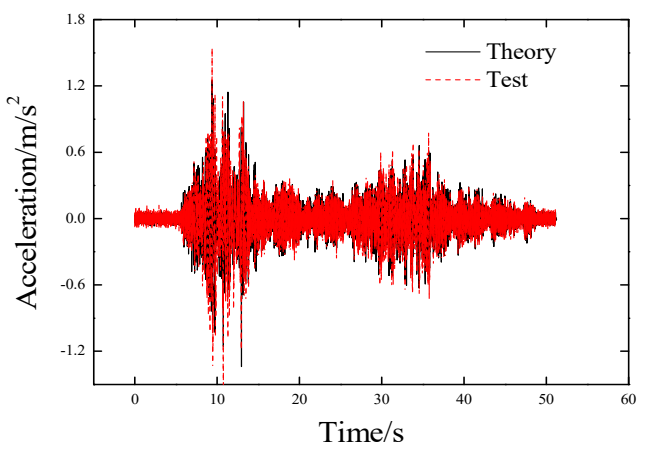

b) Short beam

Fig. 8. Comparison of beam acceleration (WC- $0.1 \mathrm{~g}$ )

Table 5. Comparison of beam seismic response

\begin{tabular}{|c|c|c|c|c|c|}
\hline \multirow{2}{*}{ Case } & Beam & \multicolumn{2}{|c|}{ Max acceleration $/ \mathrm{m} / \mathrm{s}^{2}$} & \multicolumn{2}{c|}{ Max displacement $/ \mathrm{mm}$} \\
\cline { 2 - 6 } & & Theory & Test & Theory & Test \\
\hline \multirow{2}{*}{ WC-0.1 g } & Long & 1.19 & 1.02 & 2.9 & 2.2 \\
\cline { 2 - 6 } & Short & 1.15 & 1.54 & 0.6 & 0.7 \\
\hline \multirow{2}{*}{ EL-0.1 g } & Long & 1.44 & 1.67 & 8.6 & 9.0 \\
\cline { 2 - 6 } & Short & 1.89 & 2.13 & 1.0 & 0.7 \\
\hline \multirow{2}{*}{ KB-0.1 g } & Long & 1.90 & 1.87 & 9.3 & 9.0 \\
\cline { 2 - 6 } & Short & 1.41 & 1.64 & 0.7 & 0.9 \\
\hline
\end{tabular}

Results show that: the numerical rules of the theoretical results coincide well with the test results, only the numerical values have a discrepancy. During the simulation analysis, the bearing (high damping rubber bearing) is considered to have linearity, which was not the case in the test. However, this has little effect on the numerical rules. This paper attempted to regulate the bearing stiffness value, and from the simulation results we can see that the wave forms of the acceleration and displacement time interval curves coincide well with each other, only the numerical values have a little discrepancy. 


\subsection{Effect of track constraint on the beam's natural vibration frequency}

After the test rail's installation, by once again sweeping the test model at white noise frequency, the natural vibration frequency results for the bridge beams were obtained as shown in Table 6. The results show, that with track constraint, the natural vibration frequencies of the bridge girders are improved. Due to the low longitudinal stiffness of the long beam, the track frame formed of 12 sleepers provided a greater constrained force, and the natural vibration frequency increased by $3.66 \mathrm{~Hz}$. Meanwhile, the longitudinal stiffness of the short beam is relatively larger, and only 6 sleepers provided the longitudinal constraint, the natural vibration frequency increased slightly to approximately $1.06 \mathrm{~Hz}$.

Table 6. Comparison of natural vibration frequency

\begin{tabular}{|c|c|c|}
\hline Beam & Without rail $(\mathrm{Hz})$ & With rail $(\mathrm{Hz})$ \\
\hline Long beam & 1.88 & 5.44 \\
\hline Short beam & 6.07 & 7.13 \\
\hline
\end{tabular}

\subsection{Beam displacement and rail stress results}

The test was conducted by applying seismic waves after the white noise frequency sweep test, as detailed in Table 3.

\subsubsection{Beam displacement}

Due to a relatively large volume of data, only the beam maximum displacements were extracted, as shown in Table 7.

Table 7. Maximum beam displacement (unit: $\mathrm{mm}$ )

\begin{tabular}{|c|c|c|c|c|c|c|}
\hline \multirow{3}{*}{ Case } & \multicolumn{3}{|c|}{ Long beam } & \multicolumn{3}{|c|}{ Short beam } \\
\hline & \multicolumn{2}{|c|}{ With rail } & \multirow{2}{*}{ Without rail theory } & \multicolumn{2}{|c|}{ With rail } & \multirow{2}{*}{ Without rail theory } \\
\hline & Test & Theory & & Test & Theory & \\
\hline EL-0.1 g & 1.2 & 0.9 & 4.2 & 0.6 & 0.5 & 0.8 \\
\hline EL-0.2 g & 2.2 & 1.5 & 11.1 & 1.0 & 0.9 & 1.5 \\
\hline EL-0.4 g & 9.0 & 4.2 & 44.8 & 2.0 & 1.8 & 2.9 \\
\hline $\mathrm{KB}-0.1 \mathrm{~g}$ & 1.2 & 0.7 & 6.7 & 0.5 & 0.3 & 0.6 \\
\hline KB-0.2 g & 3.0 & 2.2 & 21.8 & 1.2 & 0.6 & 1.4 \\
\hline KB-0.4 g & 14.2 & 3.5 & 49.0 & 2.3 & 1.3 & 2.6 \\
\hline WC- $0.1 \mathrm{~g}$ & 0.8 & 0.6 & 3.8 & 0.3 & 0.2 & 0.5 \\
\hline WC-0.2 g & 2.0 & 1.3 & 10.2 & 0.9 & 0.6 & 1.4 \\
\hline WC- $0.4 \mathrm{~g}$ & 8.7 & 3.6 & 37.4 & 2.0 & 1.1 & 2.3 \\
\hline
\end{tabular}

When considering the track constraint, the beam seismic displacement had significantly declined, proving the track restraint is beneficial to bridge seismic resistance. The beam displacement difference between test and theoretical computation is shown in Fig. 9.

According to the test and theoretical results, the test's maximum beam displacement was greater than theoretical results, and the beam displacement difference between test and theoretical computation is increased with the acceleration.

This is mainly due to the dynamic change in relative displacement between the rail and beam under seismic loading, and ballast bed will be subject to durable dynamic reciprocated changes, which can weaken ballast resistance. Granular railway ballast is characterized by dispersion, composition, and large dimensional differences (Lim, 2004; Indraratna, 2005), the dynamic hysteretic change of the ballast longitudinal resistance is complex and quite different from that of the ideal elasto-plastic hysteretic route. The ballast longitudinal resistance is cyclic and hysteretic under the dynamic seismic excitation load and degenerates cyclically, which makes the test's beam displacement greater than theoretical results (based on the ideal elasto-plastic hysteretic 
ballast resistance). Furthermore, the dynamic softening behavior of granular ballast bed is dependent on the exerted acceleration amplitude, the higher the exerted acceleration amplitude, the severer the dynamic softening characteristics. Therefore, the greater the seismic acceleration, the bigger the beam displacement deviation between test and theoretical computation. The assumed ideal elastic-plastic resistance used in theoretical calculations would underestimate the actual displacement; the greater the seismic intensity, the more seriously undervalued the beam displacement becomes.

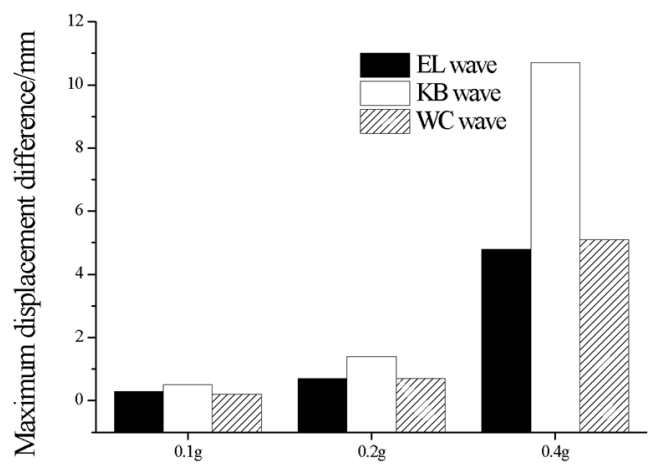

Acceleration

a) Long beam

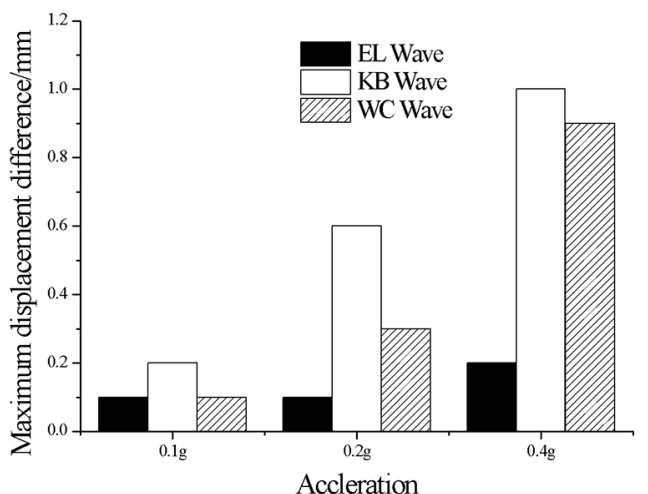

b) Short beam

Fig. 9. Test and theoretical beam displacement difference

\subsubsection{Rail stress test results}

The comparison of rail maximum tensile stress and compressive stress is shown in Figs. 10-12.

With the increase of seismic intensity, the rail stress of each measuring point correspondingly increases significantly. With the exception of a few measuring points with individual conditions (EL-0.4 g and WC-0.4 g), the rail stress test results were lower than the theoretical results. This indicates that the ideal elastic-plastic resistance used in the theoretical calculation overestimates the ballast dynamic longitudinal resistance, which could explain why the test beam displacement is greater than the theoretical value in Table 7.

According to the results obtained based on simulated calculations, the stress of measuring point SR20 close to the free end of the rail is the lowest. The ballast resistance at the sleeper node at any integral time for the simulation model does not change. Therefore, as shown in the figure, all rail stresses from measuring points SR1 to SR20, which are calculated in the simulation, change linearly. All points of the rail with peak stress, which are calculated in the simulation, are selected at the same time. The rail stress decreases linearly, indicating that the long/short beams displace in the same direction; namely the resistances of all sleeper nodes point to the same direction.

Measuring points SR9 to SR20 are set on the long beam, according to the test results, the rail stress decreases between these two points, which coincides with the theoretical results. Meanwhile, the tested stresses of measuring points SR1 to SR8 approximates an increasing trend. This indicates that the displacement results of the long/short beams at time points under peak stresses are opposite, and the ballast resistances and sleeper nodes are also opposite, which does not coincide with the theoretical results. Moreover, the displacement time intervals of the long/short beams shown in Fig. 8 this point, indicating that the stresses of measuring points SR1 to SR8 are far lower than the theoretical values.

Moreover, the track-bridge displacement caused by earthquakes can disturb the ballast bed and influence track resistance, therefore, before and after each excitation test, the structure was scanned with white noise in order to observe the changing natural frequencies of the two beams. The result shows that, by taking EL0.1 $\mathrm{g}$ and EL0.4 $\mathrm{g}$ as examples, the natural frequencies of the 
beams decrease after the test, which indicates that the ballast longitudinal resistance decreases under seismic loading. In addition, when the peak maximum acceleration of the seismic wave is low, the overall natural frequencies of the beams will not significantly decrease, however, when the peak acceleration is high, the natural frequencies will show a significant decrease due to a corresponding decrease in natural frequencies along with the increasing relative displacement of the long beam.

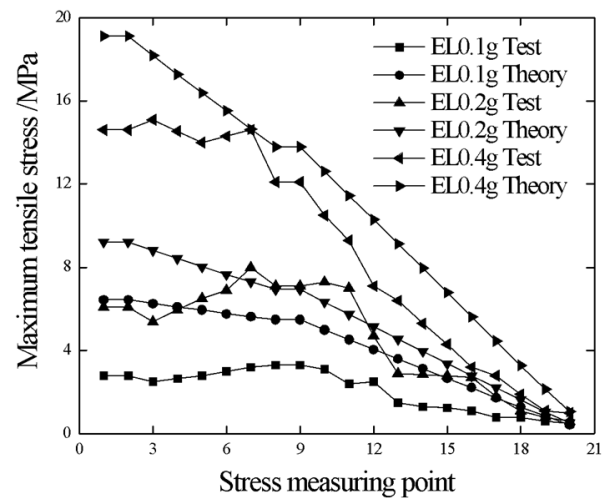

a) Tensile stress

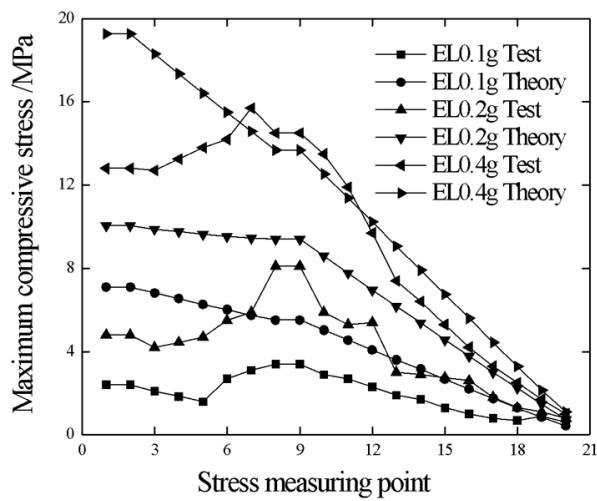

b) Compressive stress

Fig. 10. Rail stress under EL wave

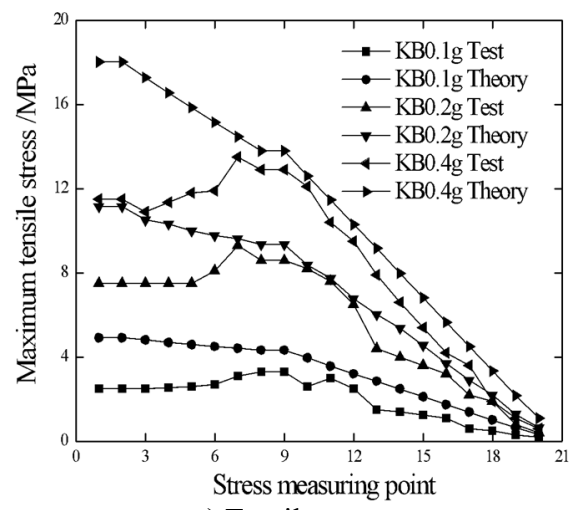

a) Tensile stress

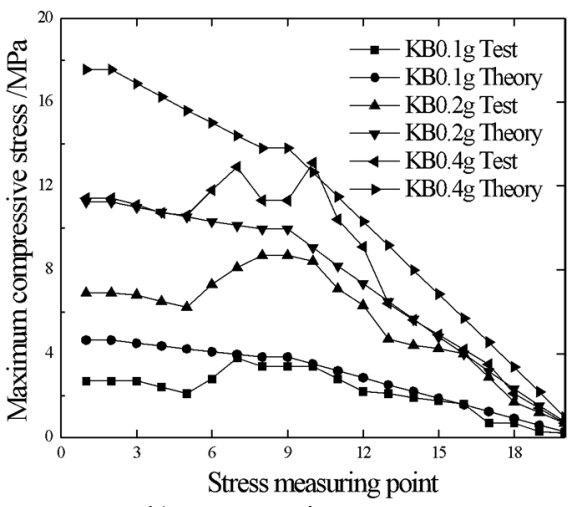

b) Compressive stress

Fig. 11. Rail stress under KB wave

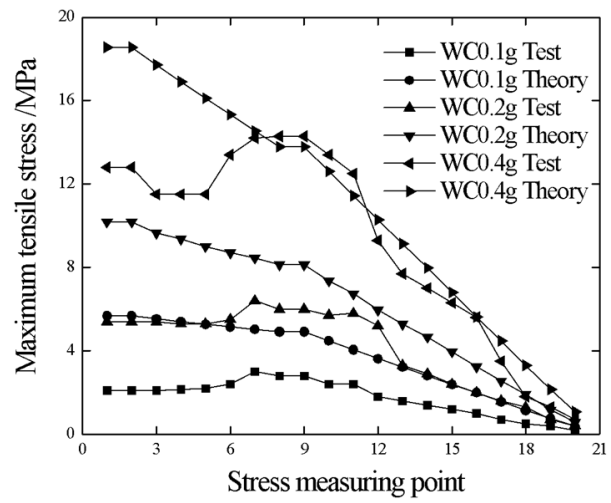

a) Tensile stress

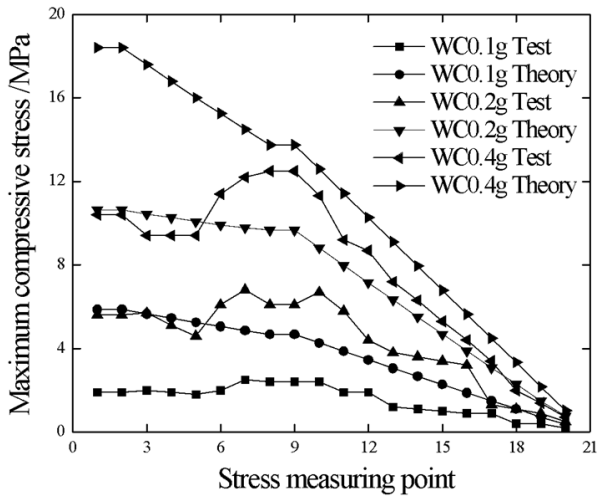

b) Compressive stress

Fig. 12. Rail stress under WC wave 


\subsubsection{The seismic response of the ballast longitudinal resistance}

The theoretical results of the hysteretic force-displacement response of a ballast element near the measuring point SR20 is plotted in Fig. 13. Results show that: the ballast resistance-displacement hysteretic curve coincides well with the ideal elastic-plastic resistance in Fig. 6, and the value of the yielding force is nearly $1.2 \mathrm{kN}$, which is the maximum force transmissible by a single ballast element.

As mentioned above, ballast beds are subject to a dynamic reciprocating state under seismic loading, the contact relations between the granules will change, wherein some will flow and redistribute. The dynamic hysteretic change of the ballast longitudinal resistance is complex and quite different from that of the ideal elasto-plastic hysteretic route. Therefore, in order to make a comparison with the theoretical results, the test results of the hysteretic force-displacement response of a ballast element is plotted in Fig. 14.

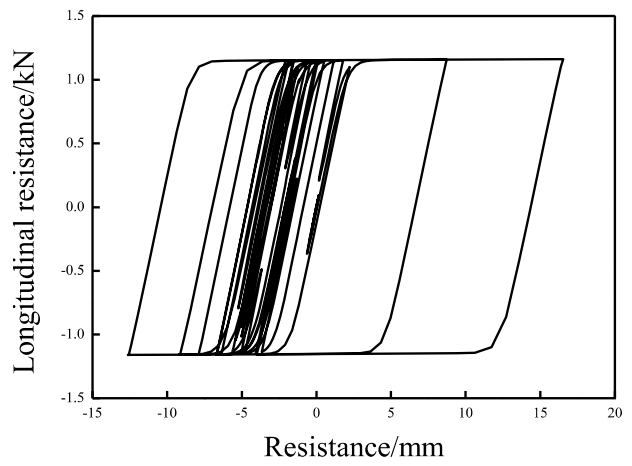

Fig. 13. Ballast force-displacement responses

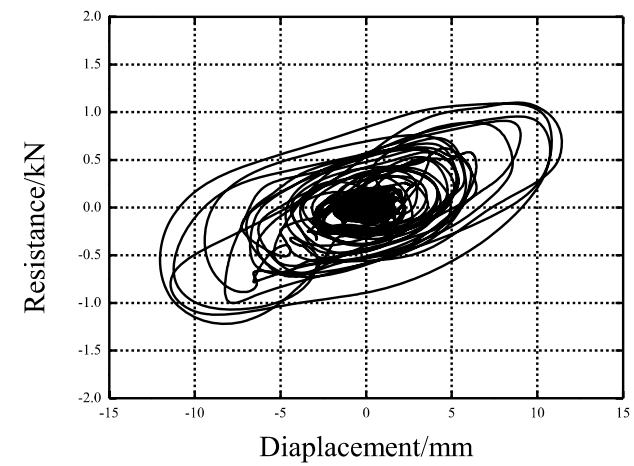

Fig. 14. Ballast resistance-displacement hysteretic curve

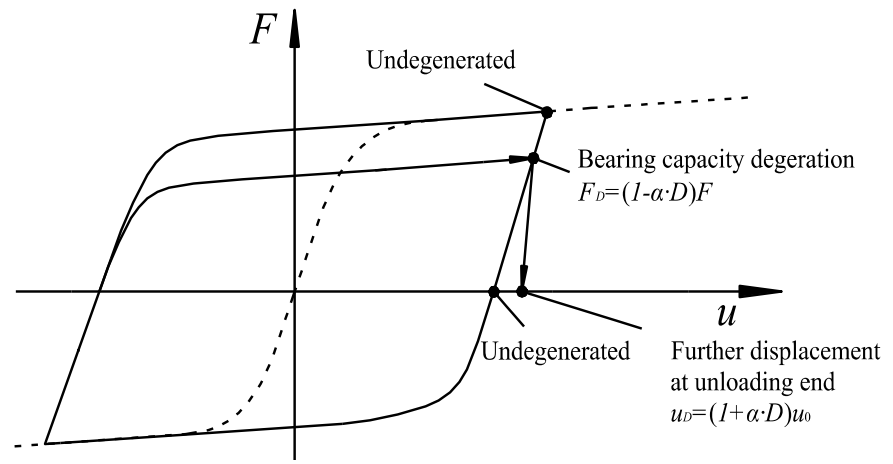

Fig. 15. Bearing capacity degeneration of ballast beds

The test results show that granular ballast beds are not ideal elastic bodies due to their microstructure characteristics such as internal pores, intergranular contact and friction. The ballast longitudinal resistance is cyclic and hysteretic under the cyclic excitation of a dynamic seismic load and degenerates cyclically (Fig. 15), influencing the rail longitudinal force value and distribution of CWR on bridges.

Moreover, the degeration of granular ballast bed under seismic loading is mainly caused by stressed and deformed granules. Images of the ballast surface were taken using a digital camera for observing and measuring ballast movement during the tests. The digital camera was set above the ballast near the beam gap and the image scales were approximately 3.5 pixels per millimeter for the 1,000-mm-wide testing area. Fig. 16 shows the displacement of the ballast grains obtainted 
by the PIV analyses (Louis, 2014) of the images taken under the the KB- $0.2 \mathrm{~g}$ case. The technique is capable of providing a clear picture of overall movements, which can reflect the motion law of ballast under seismic loading.

As shown in Fig. 16, the ballast granules move irregularly under seismic loading, wherein they scatter in different directions, some flow and redistribute and the packing state and resistance performance of the ballast bed thus changes. In addition, under seismic loading, ballast grains display insignificant movement compared to the initial loading state and experience obvious overturning and movement changes. The track bed becomes loose and reconstructed. In the hysteretic curve (Fig. 14), the test curve of the granular ballast bed shows dynamic softening properties.

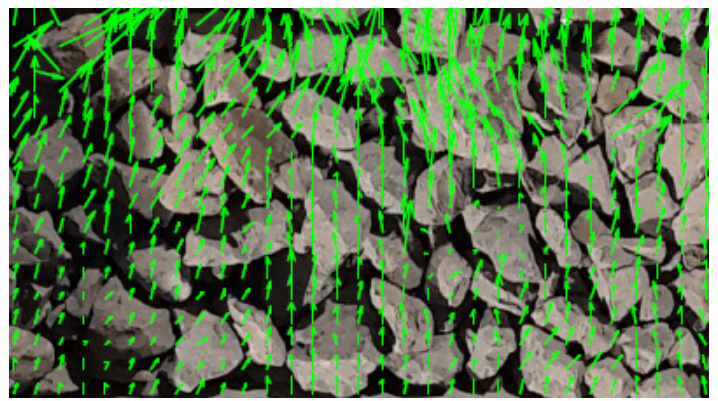

Fig. 16. Motion of ballast grains

\section{Amending the numerical model}

\subsection{Amended model selection}

The above results show that the theoretical results for rail stress and beam displacement show large discrepancies with the test results, proving the changing form of ballast longitudinal resistance during the test differs greatly from the ideal elastic-plastic resistance. In this section, the numerical model is amended according to the test results, and the nonlinear resistance elements of equivalent stiffness and equivalent damping are introduced in order to optimize the numerical model of CWR on bridges and make a reasonable selection for their parameters.

For granular ballast beds used under seismic loading, since the dynamic displacement caused by longitudinal excitation can lead to a reciprocating cyclic and hysteretic resistance of ballast beds, such dynamic resistance is in relation to the ballast bed density, ballast material, dynamic displacement frequency and amplitude etc.; the key problem to be solved for theoretical calculation is the reasonable selection of hysteretic curves of the dynamic resistance of ballast beds. Considering the major role of ballast resistance is to restrict the beam displacement and dissipate energy under seismic loading, the equivalent stiffness $K_{e}$ and equivalent damping $C_{e}$ are introduced, as shown in Fig. 17. Moreover, these two coefficients can be obtained through the modified finite element model technique [23], and implemented by the optimization module of ANSYS [24], though the specific details of the theory are beyond the scope of this paper.

When using the ANSYS module, the design variables, optimization variables and objective functions, in addition to the range of design variables all need to be determined for model optimization. Three types of variables are adopted for the ANSYS optimization module during the correction and optimization of the model, which are as follows:

1) Design variables (DVs): The design variables of values are subject to change during the analysis. Generally, all design variables should be limited to a certain range.

2) State variables (SVs): Values for restricting the design, which can be independent variables or functions of design variables.

3) Objective function (OBJ): This value is required to be as low as possible, and should be a 
function of the design variables; that is, the objective function changes with the design variables. Only one objective function is allowed to be defined in practice for optimization and analysis. Common functions are stress, deformation, weight, or the minimum mean value and minimum variance of a result.

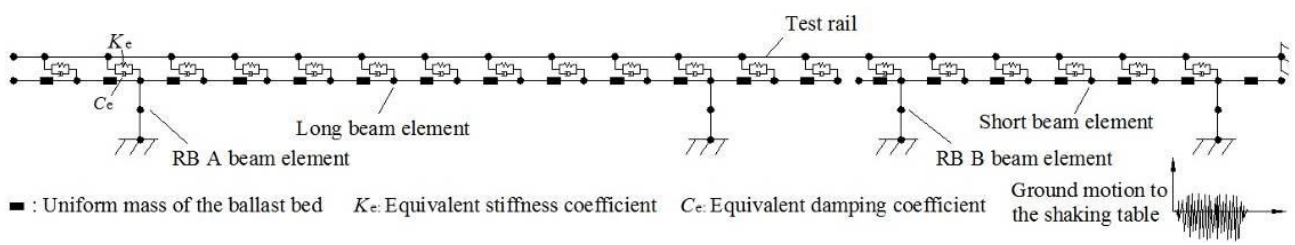

Fig. 17. Amended model of test structure

The ANSYS optimization module primarily has two optimization modes, which are as follows:

The first is a zero-order optimization method, namely the common function approximation optimization method. Essentially, it aims to fit a solution space through a surface function obtained based on least square method approximation, then calculate the limits, and then establish the maxima and minima of the surface function. It is always adopted for approximate optimization due to low accuracy.

The second optimization method is an upgrade of the first method, namely the first-order optimization method. The first-order partial derivatives of state variables and objective functions to the design variables can be obtained accurately according to a gradient search (conjugate gradient method or the quickest decrease method).

This test focuses on the rail stress and beam displacement measured during seismic excitation. From the test results, it can be seen that during vibration, the reciprocating displacement of the long beam and the axial rail stress within the long/short beam gaps are high. The measured maximum displacement $d_{\max }$ of the long beam and the maximum axial tensile stress $\sigma_{\max }$ at measuring point SR9 were adopted as the optimization variables, and the constructed objective functions is the sum of the relative errors of the long beam maximum displacement and rail maximum axial tensile stress at measuring point SR9.

\subsection{Example of model amendment}

In this section, the KB- $0.4 \mathrm{~g}$ case in Table 3 is taken as an example to be analyzed.

\subsubsection{Design variables}

In regards to the test model, the only uncertain parameter is that of ballast longitudinal resistance. Therefore, the $K_{e}$ and $C_{e}$ of this parameter could be introduced as the design variables of optimization analysis. According to the rail stress test results, the estimation of the initial value and the range of $K_{e}$ and $C_{e}$ are seen in Table 8.

Table 8. Design variables

\begin{tabular}{|c|c|c|}
\hline Variable & Initial value & Range \\
\hline$K_{e}$ & $50000(\mathrm{~N} / \mathrm{m})$ & $1 \mathrm{E} 3-1 \mathrm{E} 5(\mathrm{~N} / \mathrm{m})$ \\
\hline$C_{e}$ & $100(\mathrm{~N} \cdot \mathrm{s} / \mathrm{m})$ & $5-1 \mathrm{E} 4(\mathrm{~N} \cdot \mathrm{s} / \mathrm{m})$ \\
\hline
\end{tabular}

\subsubsection{Objective function selection}

This paper focuses on the rail stress and beam displacement measured during seismic loading. From the test results, the reciprocating displacement of the long beam and the axial rail stress strain among long/short beam crevices are high. The maximum displacement of long beam $d_{\max }$ and the maximum tensile stress $\sigma_{\max }$ at measuring point S9 were selected as optimization 
variables. The objective function $f$ is the relative errors sum of $d_{\max }$ and $\sigma_{\max }$, i.e.:

$f=\frac{d_{t h}-d_{\max }}{d_{\max }}+\frac{\sigma_{t h}-\sigma_{\max }}{\sigma_{\max }}$

where: $f$-objective function; $d_{t h}$ and $\sigma_{t h}$ - the maximum displacement and the maximum tensile stress in theoretical calculation; $d_{\max }$ and $\sigma_{\max }$ - according to Table 7 and Fig. 13, with values of $14.2 \mathrm{~mm}$ and 12.9 $\mathrm{MPa}$ respectively.

\subsubsection{Steps of model amending}

The steps of the model amending analysis and calculation are shown in Fig. 18.

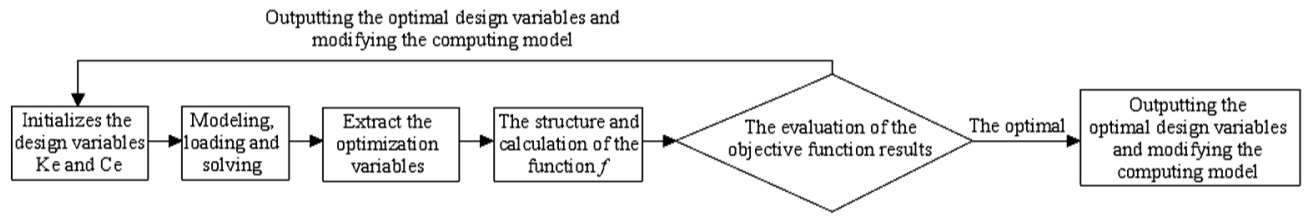

Fig. 18. Steps of model modification

\subsubsection{Results of model amendment}

Based on the amended calculation model and combined with the optimization method, the optimal equivalent stiffness coefficient $K_{e}$ and damping coefficient $C_{\mathrm{e}}$ under case KB- $0.4 \mathrm{~g}$ were obtained as $69384 \mathrm{~N} / \mathrm{m}$ and $1090.3 \mathrm{~N} \cdot \mathrm{S} / \mathrm{m}$, respectively. Comparison of the results of the long beam displacement and rail stress at measuring point S9 are shown in Fig. 19 and Fig. 20.

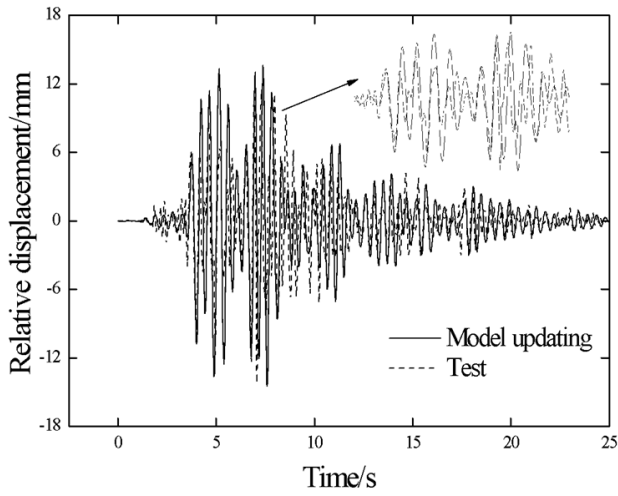

a) Long beam displacement

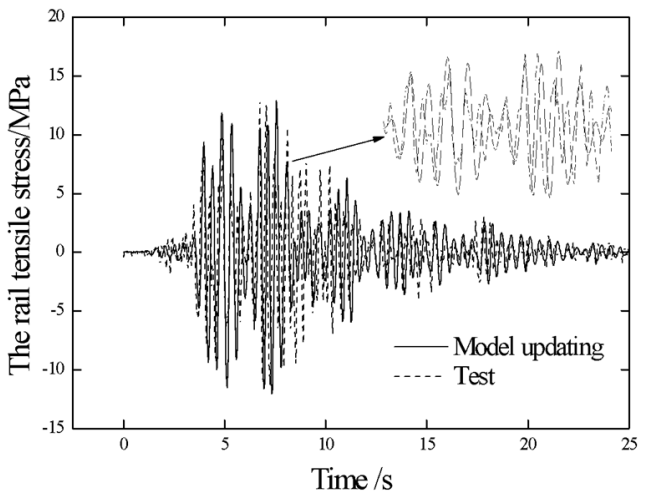

b) Stress at measuring point $\mathrm{S} 9$

Fig. 19. Displacement and stress comparison

As shown in Fig. 19 and Fig. 20, the peak value and frequency of the theoretical results coincide well with those of the test results. As shown in the close-up view of the measuring points in Fig. 15, the wave forms of the rail stress and beam displacement time interval curves also coincide well with each other. The stress values and distribution of all measuring points on the rail coincide well with the test results, indicating the equivalent stiffness $\left(K_{e}\right.$ and $\left.C_{e}\right)$ of the ballast obtained based on the optimization method can help to obtain test results through calculation of the simulation.

In regards to existing research, the related issues are always analyzed based on the ideal elastic-plastic longitudinal resistance of ballast. This hypothesis has been proved innacurate according to the test results of this paper. Moreover, based on the test results, a theoretical method, 
which is more applicable in obtaining practical results, is presented through model correction. The new theoretical calculations obtained from the modified finite element model coincide well with the test results.

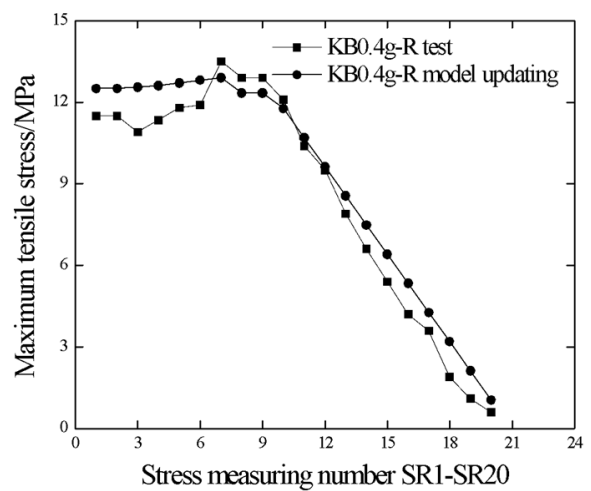

a) Tensile stress

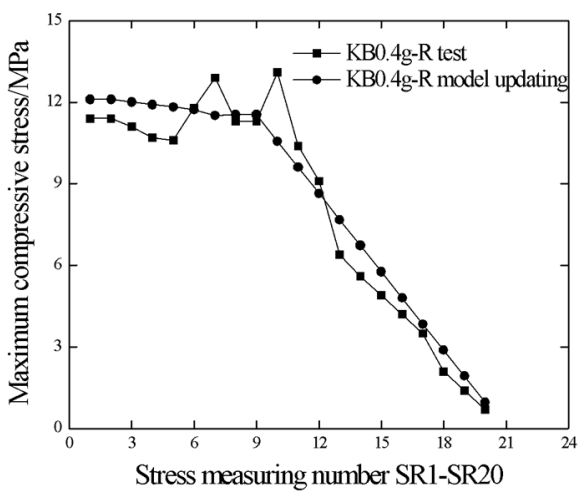

b) Compressive stress

Fig. 20. Rail stress comparison

Ping Wang conceived, designed the experiments and wrote the manuscript; Hao Liu performed the experiments and prepared the data, and wrote part of the manuscript; Xiankui Wei supported and supervised the experiments; Rong Chen supervised and directed the study. Jieling Xiao and Jingmang $\mathrm{Xu}$ analysed the experiments data and wrote part of the manuscript.

\section{Conclusions}

This paper presents a shaking table test concerning the seismic response of CWR on bridges with ballast track. The major results drawn from the test and theoretical analysis can be summarized as follows:

1) The test shows that the longitudinal constraint of ballast track could significantly improve the bridge's longitudinal natural frequency, and efficiently decrease the seismic displacement response of the bridge.

2) When ballast beds are subject to a seismic load while in a dynamic reciprocating state, the integrity will be damaged, some granules will flow and redistribute. The dynamic hysteretic change of the ballast longitudinal resistance is complex and quite different from that of the ideal elaso-plasitc hysteretic route, and the ballast longitudinal resistance performance degenerates. In the existing calculation model, the assumption of ideal elastic-plastic form applied to ballast longitudinal resistance will underestimate the actual beam displacement response; the greater the seismic intensity, the more severely will the displacement be undervalued. Nevertheless, the rail seismic force is overestimated.

3) The equivalent stiffness coefficient $K_{e}$ and damping coefficient $C_{e}$ of the ballast dynamic longitudinal resistance characteristics can be obtained by a model amendment technique, and the theoretical results coincide well with the test results by adopting the technique.

\section{Acknowledgements}

This research was supported by the National Natural Science Foundation of China (No. 51425804, No. U1234201 and No. 1334203), and the Doctorial Innovation Fund of the Southwest Jiaotong University (2014310016).

\section{References}

[1] Esveld C. Modern Railway Track. 2nd Edition, MRT-Productions, Zaltbommel, 2001. 
[2] Lim W. L. Mechanics of Railway Ballast Behaviour. Ph.D. Thesis, University of Nottingham, Nottingham, United Kingdom, 2004.

[3] Indraratna B., Salim W. Mechanics of Ballasted Rail Tracks: a Geotechnical Perspective. Taylor and Francis/Balkema, London, 2005.

[4] Zhu Y., Wei Y. X. Characteristics of railway damage due to Wenchuan earthquake and countermeasure considerations of engineering seismic design. Chinese Journal of Rock Mechanics and Engineering, Vol. 29, Issue S1, 2010, p. 3378-3386.

[5] Housner G. W., Lili X. Report on the Great Tangshan Earthquake of 1976. Chapter 1, Railway Engineering, Vol. III. Earthquake Engineering Research Laboratory, California Institute of Technology, Pasadena, CA, 2002, p. 1-60.

[6] Ruge P., Bike C. Longitudinal forces in continuously welded rails on bridge decks due to nonlinear track bridge interaction. Computers and Structures, Vol. 85, Issues 7-8, 2007, p. 458-475.

[7] Chen R., Wang P., Wei X. K. Track-bridge longitudinal interaction of continuous welded rails on arch bridge. Mathematical Problems in Engineering, 2013, http://dx.doi.org/10.1155/2013/494137.

[8] Track/Bridge Interaction Recommendations for Calculations, UIC 774-3E. International Union of Railways, Paris, 2001.

[9] Yan B., Dai G. L. Analysis of interaction between continuously-welded rail and high-speed railway bridges considering loading-history. Journal of the China Railway Society, Vol. 36, Issue 6, 2014, p. $75-80$.

[10] Sogabe M., Asanuma K., Nakamura T., et al. Deformation Behavior of Ballasted Track during Earthquakes. Quarterly Report of RTRI, Vol. 54, Issue 2, 2013, p. 104-111.

[11] Toyooka A., Ikeda M., Yanagawa H., et al. Effect of Track Structure on Seismic Behavior of Isolation System Bridges. Quarterly Report of RTRI, Vol. 46, Issue 4, 2005, p. 238-243.

[12] Fitzwilliam D. Track structure interactions for the Taiwan High Speed Rail project. IABSE Symposium Report, International Association for Bridge and Structural Engineering, Vol. 87, Issue 10, 2003, p. 73-79.

[13] Petrangeli M., Tamagno C., Tortolini P. Numerical analysis of track: structure interaction and time domain resonance. Proceedings of the Institution of Mechanical Engineers, Part F: Journal of Rail and Rapid Transit, Vol. 222, Issue 4, 2008, p. 345-353.

[14] Iemura H., Iwata S., Murata K. Shake table tests and numerical modeling of seismically isolated railway bridges. Proceedings of the 13th World Conference on Earthquake Engineering, 2004.

[15] Esmaeili M., Noghabi H. H. Investigating seismic behavior of ballasted railway track in earthquake excitation using finite-element model in three-dimensional space. Journal of Transportation Engineering, Vol. 139, Issue 7, 2013, p. 697-708.

[16] Nakamura T., Sekine E., Shirae Y. Assessment of aseismic performance of ballasted track with large-scale shaking table tests. Quarterly Report of RTRI, Vol. 52, Issue 3, 2011, p. 156-162.

[17] Huang Y., Yan G. P., Liu L. Effects of Rail Restraints on Longitudinal Seismic Response of Railway Bridges. Journal of the China Railway Society, Vol. 24, Issue 5, 2002, p. 124-128.

[18] Zhou Y., L. X. L. Building Structure Shaking Table Test Method and Technique. Science Press, Beijing, 2012.

[19] Qing T. High-Speed Railway Bridge Seismic Dynamic Response Research Based on Track-Bridge Interaction. Master Thesis, Central South University, China, 2012.

[20] Jin J. M., Tan P., Zhou F. L., et al. Test study on the equivalent damping ratio of linear natural rubber bearings. Xi' an University of Architecture and Technology, Vol. 41, Issue 5, 2009, p. 663-667.

[21] Newmark N. M. Method of computation for structural dynamics. Journal of the Engineering Mechanical Division, Vol. 85, Issue 3, 1959, p. 67-94.

[22] Liu W. S. Track-bridge Interaction between Continuous Welded Rail and Long-span Stress-truss Arch Bridge of High-speed Rails. Master Thesis, Central South University, China, 2013.

[23] Wu X. J. Summary of structural finite element modified model. Special Structures, Vol. 26, Issue 1, 2009, p. 39-45.

[24] Deng Yang Fang Study on Optimization Theory and Application of ANSYS Program in Bridge Optimal Design. Chongqing Jiao Tong University, Chongqing, 2009.

[25] Le Pen L., Bhandari A. R., Powrie W. Sleeper end resistance of ballasted railway tracks. Journal of Geotechnical and Geoenvironmental Engineering, Vol. 140, Issue 5, 2014, p. 04014004. 

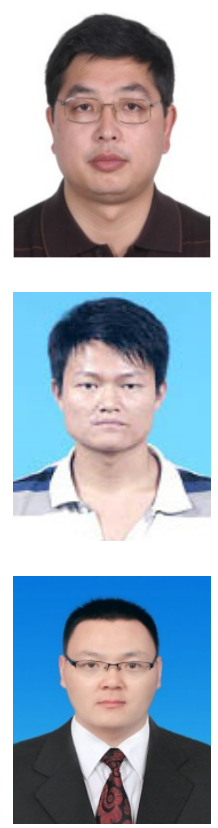

Xiankui Wei received his Ph.D. degree (2014) in highway and railway engineering from from Southwest Jiaotong University, China. Now he is an engineer in Southern Sichuan Intercity Railway CO., LTD. His current research interests include the design theory and method of high speed railway, high speed railway construction management and organization.

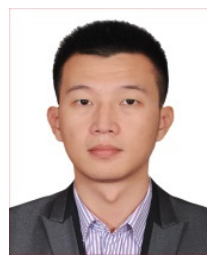

Rong Chen received Ph.D. degree in highway and railway engineering from Southwest Jiaotong University, China. Now he is an Associate Professor in the School of Civil Engineering at Southwest Jiaotong University, China. His research interests include ballast track, the design theory and method of high speed railway turnout and vibration reduction of urban rail transit.

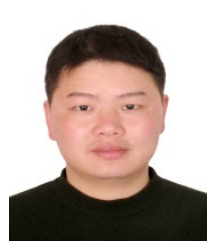

Jieling Xiao received his Ph.D. degree (2012) in highway and railway engineering from Southwest Jiaotong University, China. Now he is a Lecturer in the School of Civil Engineering at Southwest Jiaotong University, China. His current research interests include ballast track, rail geotechnics and the design theory and method of high speed railway.

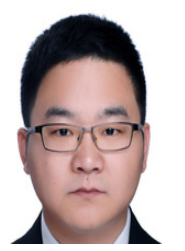

Jingmang Xu received his Ph.D. degree (2015) in highway and railway engineering from Southwest Jiaotong University, China. He has been out of post-doctoral stations (2017) from MOE Key Laboratory of High-Speed Railway Engineering, Southwest Jiaotong University, China. His current research interests include nonlinear system dynamics, rolling contact behavior and damage mechanism of high speed railway. 